\title{
Induction of Apoptosis in Lung Cancer Cells by TRAIL and L-Leucyl-L-Leucine Methyl Ester
}

\author{
Xinhua Sarah Sun ${ }^{1,3}$, Laura Bandura-Morgan ${ }^{1}$, Wolfgang Zacharias ${ }^{1,2}$ \\ ${ }^{1}$ Department of Medicine, James Graham Brown Cancer Center, University of Louisville School of Medicine, Louisville, USA; \\ ${ }^{2}$ Department of Pharmacology and Toxicology, University of Louisville School of Medicine, Louisville, USA; ${ }^{3}$ Center for Research \\ Excellence in Food Bioactive Components, University of North Carolina at Greensboro, Greensboro, USA. \\ Email:w0zach01@gwise.louisville.edu
}

Received February $9^{\text {th }}, 2011$; revised April $7^{\text {th }}, 2011$; accepted April $15^{\text {th }}, 2011$.

\begin{abstract}
Tumor necrosis factor-related apoptosis-inducing ligand (TRAIL) is a member of the tumor necrosis factor superfamily that induces apoptosis in many tumor cells. Previous studies suggested that TRAIL treatment might also cause release of lysosomal cathepsin proteases to the cytosol, thus further promoting apoptosis. L-leucyl-L-leucine methyl ester (LeuLeuOMe) is a lysosome-destabilizing agent that may cause release of cathepsins into the cytosol and ensuing apoptosis. We hypothesized that a combination of TRAIL and LeuLeuOMe may synergistically promote apoptosis in lung cancer cells. The human epidermoid lung carcinoma cell line Calu-1 (TRAIL-resistant) and human large cell lung carcinoma cell line NCI-H460 (TRAIL-sensitive) were assayed for sensitivity to TRAIL and LeuLeuOMe, given alone or in different combination doses. Each agent alone induced a dose-dependent cytotoxicity, with substantially different efficacies of the two agents for the two cell types. When both agents were combined, synergistic cytotoxicity was achieved even in the TRAIL-resistant cells. TRAIL-induced cytotoxicity was completely inhibited by pan-caspase inhibitor z-VAD-fmk, but not by cysteine protease inhibitor E-64d. Conversely, E-64d totally blocked LeuLeuOMeinduced cytotoxicity. TRAIL caused mitochondrial damage, while enlarged lysosomes and lysosomal rupture were observed in LeuLeuOMe-treated cells. Our data suggest that, while TRAIL and LeuLeuOMe cause apoptosis through pathways that differ in their involvement of lysosomal cysteine proteases, mitochondrial and lysosomal destabilization have converging pro-apoptotic effects. Thus, the synergy of TRAIL and LeuLeuOMe may be used therapeutically to promote apoptosis in lung cancers, even those with intrinsic or acquired resistance to TRAIL.
\end{abstract}

Keywords: Apoptosis, Lung Cancer, Lysosome, Mitochondria, TRAIL

\section{Introduction}

Many lung tumors and their metastases are resistant to chemo- or radiation-therapy due to their ability to evade apoptosis [1-3]. Thus, facilitating apoptosis or restoring inherently inactive apoptosis pathways in resistant tumors would enhance the efficacy of cytotoxic agents $[4,5]$.

TRAIL (tumor necrosis factor-related apoptosis -inducing ligand) is a member of the TNF family with a dual role in tumor defense [6,7]. It is of special interest for cancer therapy since it selectively kills cancer cells while sparing normal cells [7-9] and is also involved in immune surveillance against tumor metastasis [9-11]. Studies on TRAIL knockout mice showed a critical role for TRAIL in suppressing tumor initiation and metastasis $[12,13]$. On the other hand, hypoxia inside fast growing solid tumors or long-term exposure to cytotoxic drugs can result in acquired apoptosis resistance to TRAIL and other therapeutic agents in tumor cells [14-16]. Depending on the cell type, TRAIL-induced apoptosis in tumor cells is mediated through both mitochondria-dependent and/or -independent pathways [17-20].

Recently, destabilization of lysosomes and release of lysosomal cathepsin proteases and other lysosomal contents have been implicated in apoptotic cell death, and there is increasing evidence for the existence of a lysosomal pathway of apoptosis [14,21-23,25-30]. For lung cancer, the extent to which endogenous lysosomal cathepsins either promote or diminish the spread of tumors is unknown, as is their role in cancer progression versus apoptosis. However, destabilization of lysosomes and lysosomal rupture in response to certain pro-apoptotic stimuli may be the first step in cathepsin-mediated activation 
of the apoptosis cascade $[1,2,23,25-30]$.

We hypothesized that activation of this lysosomal apoptosis pathway in TRAIL-resistant lung cancers may enhance TRAIL-induced apoptosis. This concept is based on several considerations: 1) TRAIL-based therapies are now being tested for prevention of tumor spread and metastasis; 2) TRAIL is cytotoxic for many malignant cells but not normal cells; 3) lysosomotropic drugs may enhance TRAIL susceptibility in inherently resistant cells; 4) combined TRAIL/LeuLeuOMe treatment may restore apoptosis pathways that are deficient in some cells. Therefore, we have tested the cytotoxic effects and activation of pro-apoptotic proteases after exposure of lung cancer cell lines to TRAIL and/or the lysosomotropic drug LeuLeuOMe. Our results suggest that the combination clearly has pro-apoptotic synergy, even in the case of TRAIL-resistant cells.

\section{Materials and Methods}

\subsection{Reagents}

Recombinant human TRAIL, LysoTracker Green DND-26, and MitoTracker CMXRos were purchased from Invitrogen (Carlsbad, CA). LeuLeuOMe and z-VAD-fmk (carbobenzoxy-Val-Ala-Asp-fluoromethylketone) were purchased from Bachem (Torrance, CA). E-64d [(L-3-trans-ethoxycarbonyloxirane-2-carbonyl)-L -leucine (3-methylbutyl) amide] was from Peptides International (Louisville, KY), z-IETD-fmk (carbobenzoxy -Ile-Glu-Thr-Asp-fluoromethylketone), z-LEHD-fmk (carbobenzoxy-Leu-Glu(OMe)-His-Asp(OMe)-fluoro methylketone), and Annexin $\mathrm{V}$ recombinant antibody were from BD Pharmingen (San Diego, CA), and sulforhodamine B was from Sigma (St. Louis, MO). Fluorescence-based activity assay kits for caspase- $3,-8$, and -9 and Hoechst 33342 stain were from EMD Biosciences (San Diego, CA). HBSS (Hank's balanced salt solution) was from Lonza (Walkersville, MD).

\subsection{Cell Lines and Cultures}

The human non-small cell lung cancer (NSCLC) cell lines Calu-1 (pleural lung metastasis, adenocarcinoma; ATCC \# HTB-54) and NCI-H460 (large cell lung carcinoma; ATCC \# HTB-177) were purchased from the American Type Culture Collection (Manassas, VA). Cells were cultured in McCoy's 5A medium (Calu-1) or RPMI 1640 medium (NCI-H460), each supplemented with $2 \mathrm{mM}$ L-glutamine, 20 units $/ \mathrm{ml}$ penicillin, $20 \mu \mathrm{g} / \mathrm{ml}$ streptomycin (all from Cellgro, Herndon, VA) and $10 \%$ FBS (Atlanta Biologicals, Lawrenceville, GA). Cells were grown at $37^{\circ} \mathrm{C}$ in a humidified atmosphere with $5 \%$ $\mathrm{CO}_{2}$.

\subsection{Cytotoxicity Assays}

Cells were plated in 96-well plates at a density of 8000 cells per well in triplicate. Following attachment (after 24 h), cells were treated with different concentrations of TRAIL (20, 40, 100 or $200 \mathrm{ng} / \mathrm{ml}$ for Calu-1 cells; 2, 10, 20 or $40 \mathrm{ng} / \mathrm{ml}$ for NCI-H460 cells), or LeuLeuOMe (0.2, $0.4,1.0$ or $2.0 \mathrm{mM}$ ), or a combination of both agents. Control cells received only the solvent dimethylsulfoxide (DMSO). Where indicated, cell-permeable enzyme inhibitors were added $2 \mathrm{~h}$ before treatments. Cytotoxicity was assessed after $6 \mathrm{~h}$ using the sulforhodamine B (SRB) assay [31]. Briefly, the medium was discarded, and the adherent cells were fixed by $100 \mu \mathrm{l}$ of cold $10 \%$ trichloroacetic acid $(\mathrm{w} / \mathrm{v})$ in each well for $1 \mathrm{~h}$ at $4^{\circ} \mathrm{C}$. The plate was then washed 5 times with deionized water and air-dried. Cells were stained with $50 \mu \mathrm{l} /$ well of $0.4 \%$ (w/v, in $1 \%$ acetic acid) SRB solution for $20 \mathrm{~min}$ at $22^{\circ} \mathrm{C}$, and then washed 5 times with $1 \%$ acetic acid. After air-drying, $100 \mu \mathrm{l}$ of $10 \mathrm{mM}$ Tris (pH 10.5) was added to each well and the absorbance was read at $530 \mathrm{~nm}$. Cytotoxicity is expressed as the percent of cells in treated wells relative to number of cells in the solvent only control set to $100 \%$. Each experiment was performed independently at least 2 times in triplicate and cytotoxicities are given as means $\pm \mathrm{SD}$.

\subsection{Caspase Activity Assays}

Caspase-3, -8 , or -9 activity in cultured cells was measured using the respective fluorometric caspase activity assay kits according to the manufacturer's instruction. The cell pellet of 1 million cells was resuspended in 50 $\mu \mathrm{l}$ sample buffer. After centrifugation, $50 \mu \mathrm{l}$ of cleared lysates was transferred to a 96-well plate, mixed with 50 $\mu \mathrm{l}$ assay buffer and $10 \mu \mathrm{l}$ of fluorescence labeled corresponding caspase substrate DEVD, IETD, or LEDH. Using excitation at $400 \mathrm{~nm}$ and emission at $505 \mathrm{~nm}$, the plate was read immediately, and again after incubation at $37^{\circ} \mathrm{C}$ for $2 \mathrm{~h}$. Caspase activity was expressed as increase in relative fluorescence units (RFU) per million cells between the two readings.

\subsection{Fluorescence Microscopy}

The integrity of mitochondria and lysosomes was visualized based on the uptake of MitoTracker Red CMXRos and LysoTracker Green DND-26. Briefly, MitoTracker was added to the cells at a final concentration of $25 \mathrm{nM}$. After $25 \mathrm{~min}$ of incubation at $37^{\circ} \mathrm{C}$, LysoTracker and Hoechst 33342 were added to the cells at final concentrations of $75 \mathrm{nM}$ and $0.5 \%$, respectively. After incubation for $5 \mathrm{~min}$, culture medium was removed, changed to HBSS, and cells were observed with a Nikon fluorescence microscope (Nikon, Melville, NY). Cell images 
were captured with a Nikon TE-FM Epi-Fluorescence system, pseudocolored using Metamorph software (Universal Imaging Corporation, Buckinghamshire, UK) according to the corresponding dye color.

\subsection{Flow Cytometry}

Cells were treated for $6 \mathrm{hrs}$ with LeuLeuOMe $(2 \mathrm{mM})$, TRAIL (200 ng/ml for Calu-1; $40 \mathrm{ng} / \mathrm{ml}$ for H460), or combined agents (2mM LeuLeuOMe plus $200 \mathrm{ng} / \mathrm{ml}$ TRAIL for Calu-1, or $2 \mathrm{ng} / \mathrm{ml}$ for H460). Cells were trypsinized, washed in ice-cold PBS, resuspended in $1 \mathrm{X}$ Binding Buffer $\left(1 \times 10^{5}\right.$ cells $/ 0.1 \mathrm{ml}$ in $10 \mathrm{mM}$ Hepes $\mathrm{pH}$ 7.4, $2.5 \mathrm{mM} \mathrm{CaCl}_{2}, 140 \mathrm{mM} \mathrm{NaCl}$ ), and Annexin V-APC $(5 \mu \mathrm{l})$ added per $10^{5}$ cells for $15 \mathrm{~min}$ at RT. Cells were analyzed on a FACS Calibur using FlowJo software (BD Biosciences; Franklin Lakes, NJ).

\subsection{Statistical Analysis}

Data were expressed as mean values \pm S.D. Statistical analysis was determined by two-tailed Student's $t$-test. A value of $p<0.05$ was considered to be statistically significant.

\section{Results}

\subsection{Differential Resistance of Lung Cancer Cell Lines to TRAIL or LeuLeuOMe}

Cytotoxicity assays confirmed that NCI-H460 cells were very sensitive to TRAIL with nearly $90 \%$ cell death at $<50 \mathrm{ng} / \mathrm{ml}$, whereas Calu-1 cells were highly resistant to TRAIL up to $200 \mathrm{ng} / \mathrm{ml}$ for a 6 hour exposure (Figure 1(a)) [32]. Interestingly, similar differential sensitivity was also observed for LeuLeuOMe treatment, although the difference between cell lines was not as pronounced as for TRAIL (Figure 1(b)).

To investigate whether the remaining viable H460 cells following exposure to TRAIL at $200 \mathrm{ng} / \mathrm{ml}$ for 6 hour (Figure 1(a)) represented a sub-population, the surviving treated cells were allowed to recover for $90 \mathrm{~h}$ and then re-exposed to either 40 or $200 \mathrm{ng} / \mathrm{ml}$ TRIAL for $6 \mathrm{~h}$. The recovered cells showed $54 \%$ cytotoxicity at $40 \mathrm{ng} / \mathrm{ml}$ TRAIL and $71 \%$ cytotoxicity at $200 \mathrm{ng} / \mathrm{ml}$ TRAIL, compared to $84 \%$ and $91 \%$, respectively, for cells not pre-exposed to TRAIL (not shown). This indicates that the residual resistance to TRAIL did not involve a particularly resistant sub-population of $\mathrm{H} 460$ cells.

\subsection{TRAIL Induces Cathepsin-Independent Apoptosis in Lung Cancer Cell Lines}

The effects of various protease inhibitors on TRAIL cytotoxicity were determined (Figure 2). Calu-1 or NCIH460 cells were treated with TRAIL (40 ng/ml for 6 hours) in the absence or presence of pan-caspase inhibittor z-VAD-fmk or cysteine protease inhibitor E-64d. For both cell lines, z-VAD-fmk completely inhibited TRAIL cytotoxicity, whereas only negligible effects were observed for E-64d (Figure 2(a)).

Examination of caspase activities showed that TRAIL treatment resulted in strong activation of caspase-3, and several-fold increases of caspase- 8 and caspase-9 (Figure 2(b)). z-VAD-fmk completely blocked caspase-3 activation as well as activation of caspase- 8 and caspase-9. However, E-64d did not affect activation of these caspases. These data indicate that TRAIL- induced apoptosis in both cell lines does not involve endogenous cysteine proteases.

Fluorescence microscopy after staining with MitoTracker Red CMXRos, LysoTracker Green DND-26, and Hoechst 33342 showed that many of the Calu-1 and NCI-H460 cells had typical apoptotic morphology such as condensed and fragmented nuclei after TRAIL treatment (Figure 2(c)). In both cell types, TRAIL treatment caused mitochondria to lose their fine structure and be

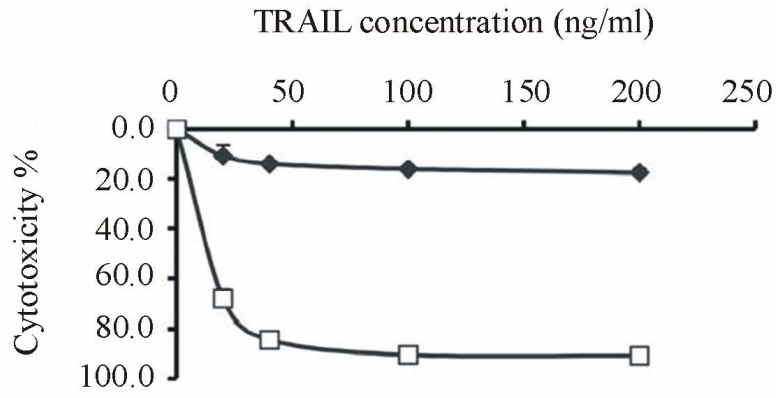

(a)

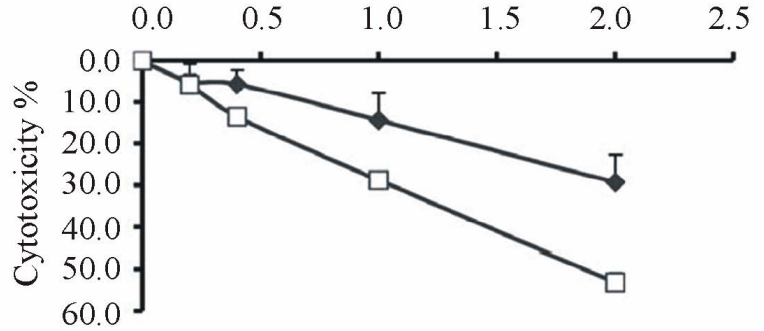

(b)

Figure 1. Differential resistance of lung cancer cell lines to TRAIL or LeuLeuOMe. Calu-1 $(\diamond)$ or NCI-H460 ( $\square$ ) cells were treated for 6 hours with different concentrations of TRAIL from 0 to $200 \mathrm{ng} / \mathrm{ml}$ (a) or LeuLeuOMe from 0 to $2.0 \mathrm{mM}$ (b), followed by SRB assays to determine dose-dependent cytotoxicity. Each point indicates the mean \pm SD of 3 replicate measurements. 

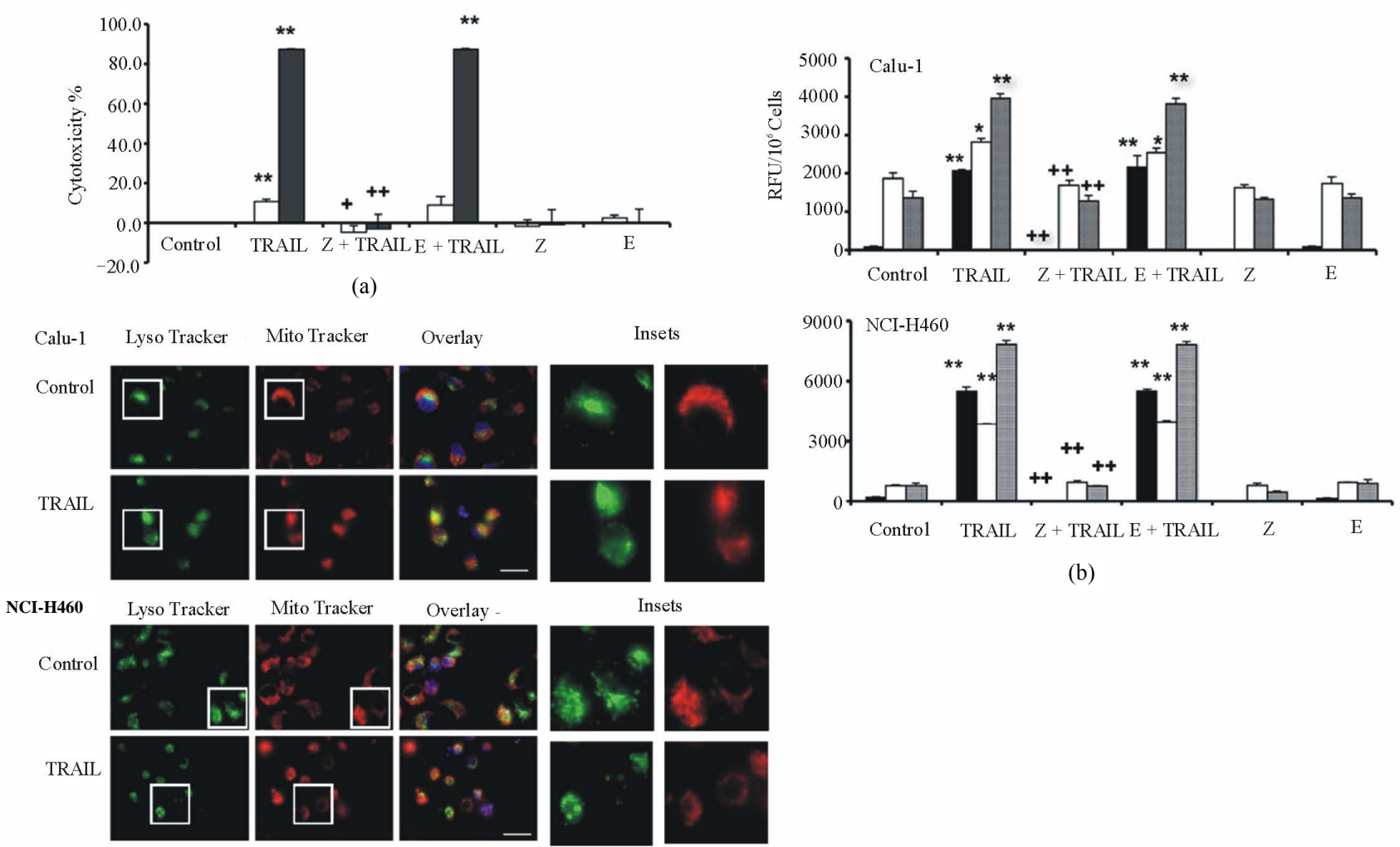

Mito Tracker
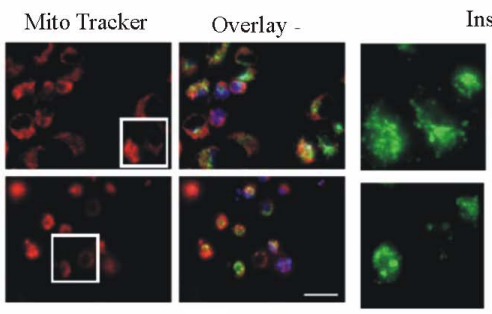

Insets

(b)

Figure 2. TRAIL-induced cathepsin-independent apoptosis in lung cancer cell lines. Calu-1 and NCI-H460 cells were treated with $40 \mathrm{ng} / \mathrm{ml}$ TRAIL for 6 hours. a: Cytotoxicity was measured using SRB assay after pre-treatment of cells with $20 \mu \mathrm{M}$ protease inhibitors z-VAD-fmk (Z) or E-64d (E) for 2 hours, followed by TRAIL treatment. Calu-1, open bars; NCI-H460, closed bars. b: Activity assays for caspase-3 (black bars), caspase-8 (open bars), and caspase-9 (grey bars) for cells treated as in a. Caspase activity is expressed in relative fluorescence units (RFU). Each bar indicates the mean \pm SD of 3 replicate measurements. $* / * *$ vs. control, ${ }^{*} p<0.05, * * p<0.01 ;+++$ vs. TRAIL, $+p<0.05,++p<0.01$. c: Fluorescence microscopy images of TRAIL-treated Calu-1 and NCI-H460 cells after co-staining with LysoTracker Green DND-26, MitoTracker Red CMXRos and Hoechst 33342 (overlays, bar: $25 \mu \mathrm{m}$ ). Individual images for LysoTracker and MitoTracker are also shown together with selected enlarged regions (boxed insets: $40 \mu \mathrm{m}$ ).

come diffuse and swollen; also, some lysosomes appeared enlarged.

\subsection{LeuLeuOMe Triggers Cathepsin-Dependent Apoptosis in Lung Cancer Cell Lines}

The effects of various protease inhibitors on LeuLeuOMe cytotoxicity were determined (Figure 3). Calu-1 or NCI-H460 cells were treated with LeuLeuOMe $(1.0 \mathrm{mM}$ for 6 hours) in the absence or presence of pan-caspase inhibitor $\mathrm{z}$-VAD-fmk or cysteine protease inhibitor E-64d (Figure 3(a)). As shown above (Figure 1(b)), LeuLeuOMe treatment caused moderate cytotoxicity in Calu-1 cells $(\sim 15 \%)$ and NCI-H460 cells $(\sim 35 \%)$. For Calu-1 cells, LeuLeuOMe cytotoxicity was completely blocked by z-VAD-fmk and partially blocked by E-64d. Intriguingly, a 2- to 3-fold enhancing effect was observed for E-64d alone, reflecting a slight toxicity at the applied dose of $20 \mu \mathrm{M}$ for Calu-1. On the other hand, Leu-
LeuOMe-induced cytotoxicity in NCI-H460 cells could be significantly inhibited by z-VAD-fmk and completely blocked by E-64d. For H460 cells, E64d at $20 \mu \mathrm{M}$ was not cytotoxic (Figure 3(a)).

Examination of caspase activation in Calu-1 and NCI-H460 cells after LeuLeuOMe treatment revealed that both cell types have similar responses (Figure 3(b)). There was a strong increase for caspase-3, a moderate increase for caspase- 9 , and no detectable change for caspase-8 in treated cells compared to control cells. Pan-caspase inhibitor z-VAD-fmk and E-64d completely blocked caspase- 3 and caspase- 9 activation following exposure to LeuLeuOMe.

When exposed to LeuLeuOMe, both cell lines also exhibited typical apoptotic morphology including condensed and fragmented nuclei. In LeuLeuOMe-treated cells, there was pronounced lysosomal rupture, while mitochondrial integrity was relatively unaffected (Figure3(c)). 

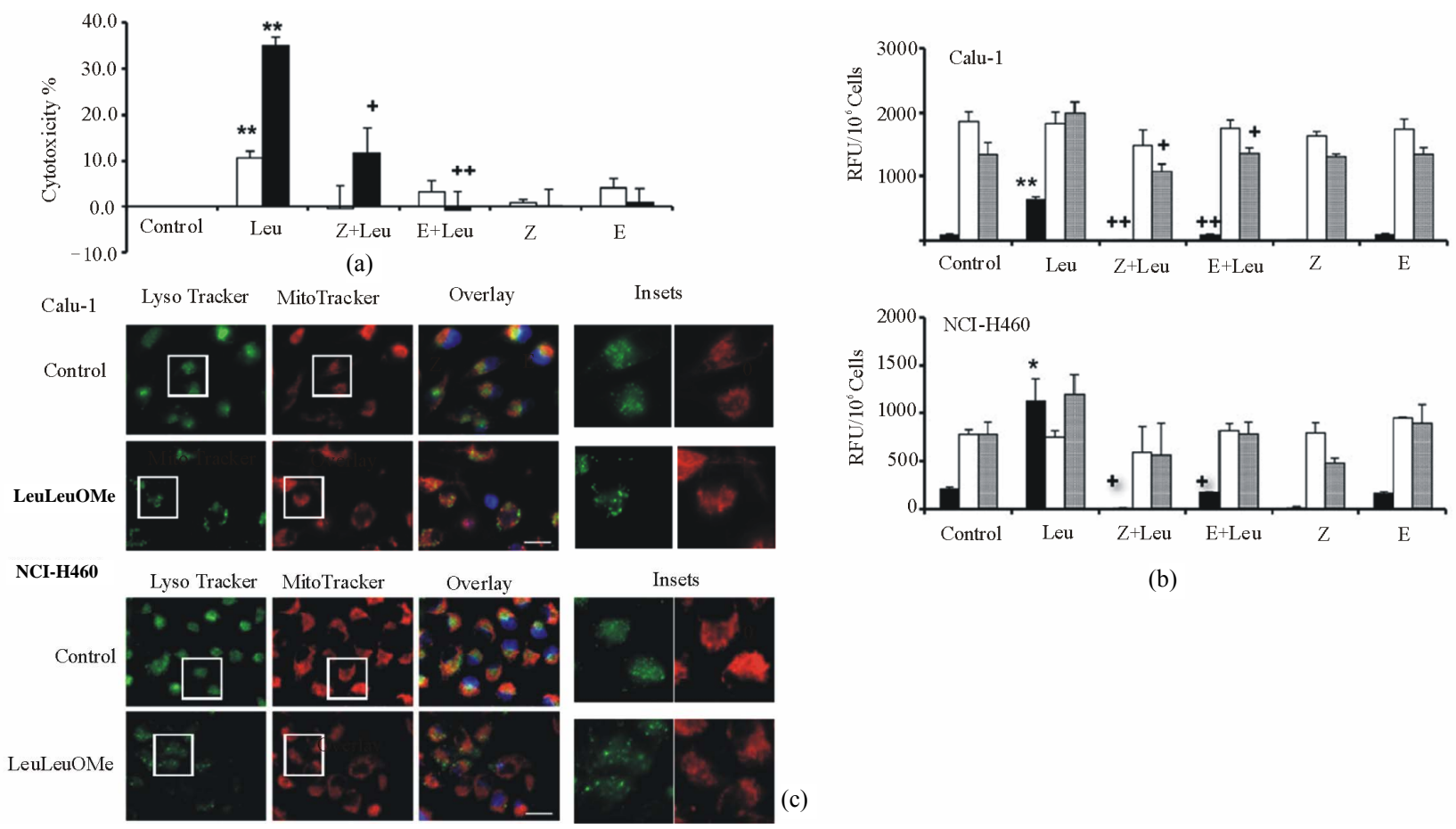

(b)

Figure 3. LeuLeuOMe-induced cathepsin-dependent apoptosis in lung cancer cell lines. Calu-1 and NCI-H460 cells were treated with 1.0 mM LeuLeuOMe for 6 hours. (a) Cytotoxicity was measured using SRB assay after pre-treatment of cells with $20 \mu \mathrm{M}$ protease inhibitors z-VAD-fmk (Z) or E-64d (E) for 2 hours, followed by LeuLeuOMe treatment. Calu-1, open bars; NCI-H460, closed bars. (b) Activity assays for caspase-3 (black bars), caspase-8 (open bars), and caspase-9 (grey bars) for cells treated as in a. Caspase activity is expressed in relative fluorescence units (RFU). Each bar indicates the mean \pm SD of 3 replicate measurements. $* / * *$ vs. control, $* p<0.05, * * p<0.01 ;+/++$ vs. LeuLeuOMe, $+p<0.05,++p<0.01$. (c) Fluorescence microscopy images of LeuLeuOMe-treated Calu-1 and NCI-H460 cells after co-staining with LysoTracker Green DND-26, MitoTracker Red CMXRos and Hoechst 33342 (overlays, bar: $25 \mu \mathrm{m}$ ). Individual images for LysoTracker and MitoTracker are also shown together with selected enlarged regions (boxed inserts: $40 \mu \mathrm{m}$ ).

\subsection{Caspases 8 and 9 Play Key Roles in TRAIL- or LeuLeuOMe-induced Apoptosis in Lung Cancer Cell Lines}

The effect of caspase- 8 inhibitor z-IETD-fmk or caspase-9 inhibitor z-LEHD-fmk on TRAIL or LeuLeuOMe cytotoxicity was also assessed (Figure 4). Calu-1 or NCI-H460 cells were treated with TRAIL (40 ng/ml for 6 hours) or LeuLeuOMe (1.0 $\mathrm{mM}$ for 6 hours) in the absence or presence of z-IETD-fmk or z-LEHD-fmk. For both cell lines, z-IETD-fmk completely inhibited the cytotoxic effects of both TRAIL and LeuLeuOMe, although only at higher concentration $(80 \mu \mathrm{M})$ for NCI-H460 cells compared to Calu-1 cells $(20 \mu \mathrm{M})$. On the other hand, the caspase-9 inhibitor only partially blocked the effects of both agents, with $\sim 70 \%-80 \%$ inhibition for TRAIL and $\sim 50 \%-60 \%$ inhibition for LeuLeuOMe.

\subsection{TRAIL plus LeuLeuOMe Synergistically Induce Partially Cathepsin-dependent Apoptosis in Lung Cancer Cell Lines}

We examined whether the cytotoxic effects of TRAIL and LeuLeuOMe would be synergistic (Figure 5). TRAIL-resistant Calu-1 cells showed approximately 15\% toxicity at $200 \mathrm{ng} / \mathrm{ml}$ TRAIL alone, and only $25 \%$ toxicity at $2 \mathrm{mM}$ LeuLeuOMe alone. However, combinations of TRAIL (from 20 to $200 \mathrm{ng} / \mathrm{ml}$ ) and LeuLeuOMe (from 0.2 to $2.0 \mathrm{mM}$ ) for 6 hours caused significant synergistic cytotoxicity. Co-treatment with TRAIL (40 ng/ml) and LeuLeuOMe $(2.0 \mathrm{mM})$ resulted in $90 \%$ toxicity for Calu-1 (Figure 5(a)). In TRAIL-sensitive NCI- H460 cells, similar synergistic effects were achieved at much lower doses of TRAIL (2 to $20 \mathrm{ng} / \mathrm{ml}$ ) and LeuLeuOMe (0.2 to 1.0 $\mathrm{mM}$ ). These cells showed $\sim 85 \%$ toxicity at $40 \mathrm{ng} / \mathrm{ml}$ TRAIL alone, while LeuLeuOMe alone at $2 \mathrm{mM}$ caused $\sim 50 \%$ toxicity. Co-treatment resulted in $95 \%$ toxicity at 2 $\mathrm{ng} / \mathrm{ml}$ TRAIL plus $2 \mathrm{mM}$ LeuLeuOMe, or at $40 \mathrm{ng} / \mathrm{ml}$ TRAIL plus $0.2 \mathrm{mM}$ LeuLeuOMe (Figure 5(a)). Synergy was verified by isobole plots for $50 \%$ cytotoxicity (ED 50) in both Calu-1 and NCI-H460 cells [33]. Both curves were distinctly concave for combination treatment data, indicating true synergy between TRAIL and LeuLeuOMe when co-administered (Figure 5(b)). 


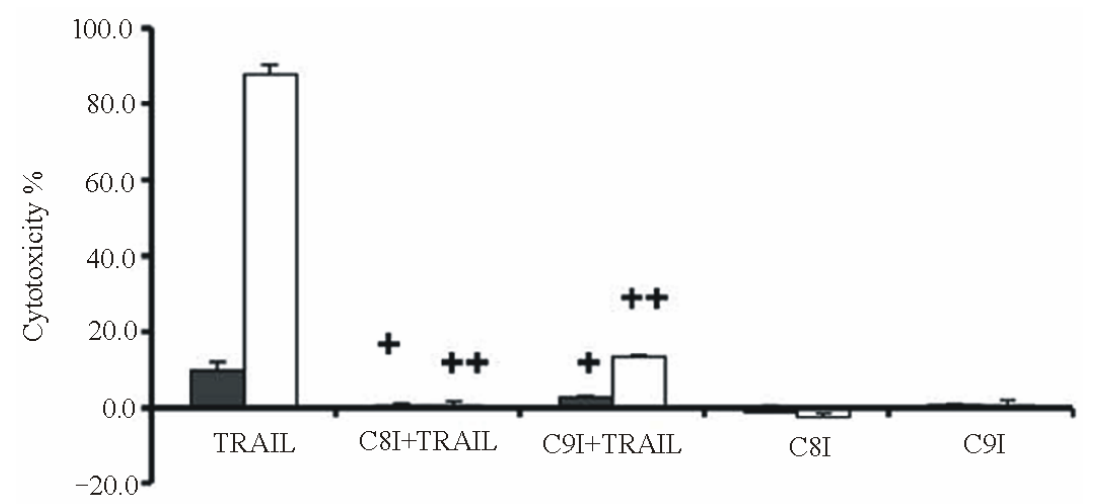

(a)

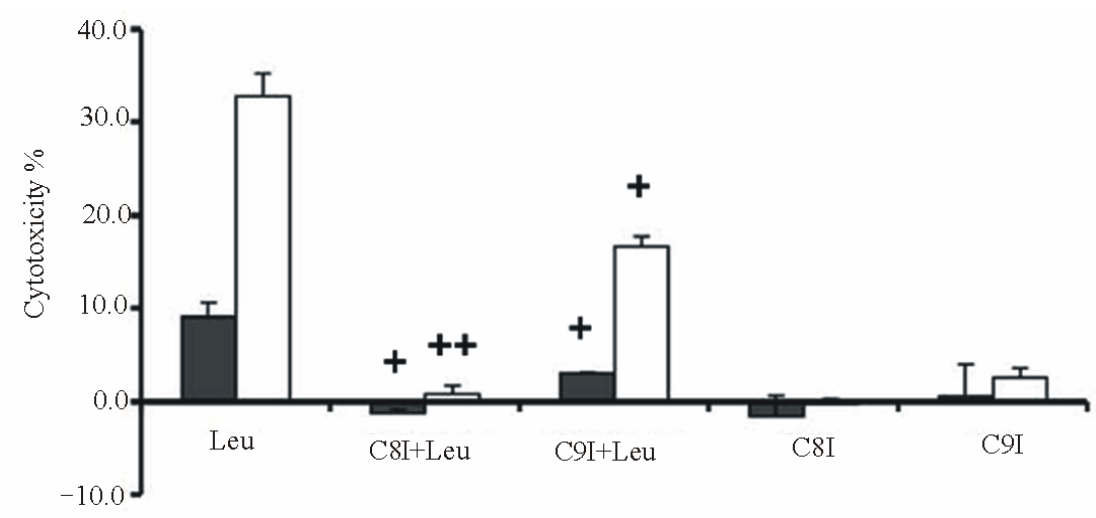

(b)

Figure 4. Caspase-8 and caspase-9 as key regulators during TRAIL- or LeuLeuOMe-induced apoptosis in lung cancer cell lines. Cytotoxicity for Calu-1 (black bars) or NCI-H460 (white bars) cells was measured using SRB assays; each bar indicates the mean \pm SD of 3 replicate measurements. Pre-treatment was done for 2 hours with caspase-8 inhibitor z-IETD-fmk or caspase-9 inhibitor z-LEHD-fmk (20 $\mu \mathrm{M}$ for Calu-1 cells; $80 \mu \mathrm{M}$ for NCI-H460 cells). (a) Cytotoxicity after treatment with 40 ng/ml TRAIL for 6 hours. $+/++$ vs. TRAIL, $+p<0.05,++p<0.01$. (b) Cytotoxicity after treatment with $1.0 \mathrm{mM} \mathrm{LeuLeuOMe}$ for 6 hours. $+/++$ vs. LeuLeuOMe, $+p<0.05,++p<0.01$.

When treated cells were allowed to recover from exposure and re-assayed for viability, the combination treatment permanently inhibited cell proliferation from which both cell types could not recover after 4 days (Figure 5(c)). This effect was not seen for treatments with TRAIL alone. Intriguingly, Calu-1 cells were also permanently affected by LeuLeuOMe alone whereas NCI-H460 cells could recover, further supporting the notion that the two agents affect different apoptotic pathways in different cell types.

Cytotoxicities were determined for combinations of two different TRAIL ( 20 or $40 \mathrm{ng} / \mathrm{ml}$ for Calu- 1 cells; 2 or 10 $\mathrm{ng} / \mathrm{ml}$ for NCI-H460 cells) plus the same LeuLeuOMe concentration $(0.4 \mathrm{mM})$, either in the absence or presence of protease inhibitors (Figure 6). As shown above, higher TRAIL dose induced higher cytotoxicity at the same dose of LeuLeuOMe. For both cell lines, the pan-caspase inhibitor z-VAD-fmk or caspase-8 inhibitor z-ITED-fmk totally blocked the synergistic toxicity achieved by TRAIL plus LeuLeuOMe, whereas the cysteine protease inhibitor E-64d only partially inhibited this combined ef- fect (Figure 6(a)). Interestingly, the cytotoxicity in the presence of E-64d at either low or high TRAIL concentration plus $0.4 \mathrm{mM}$ LeuLeuOMe was close to the cytotoxicity caused by the two corresponding TRAIL concentrations alone. E-64d only fractionally inhibited cell death, presumably blocking the effect of LeuLeuOMe but not that of TRAIL. The caspase-9 inhibitor z-LEHD-fmk also only partially inhibited cytotoxicity of both combination treatments especially in NCI-H460 cells.

Examination of caspase activities demonstrated similar effects for both the TRAIL-resistant Calu-1 and the TRAIL-sensitive NCI-H460 cell lines. Co-treatment for 6 hours with TRAIL (40 ng/ml for Calu- $1 ; 10 \mathrm{ng} / \mathrm{ml}$ for NCI-H460) plus LeuLeuOMe (0.4 mM for both Calu-1 and NCI-H460) activated caspase-3, caspase- 8 , and caspase-9. This effect was completely reversed by the pan-caspase inhibitor z-VAD-fmk, but only partially reversed by E-64-d (Figure 6(b)). As above, presumably only the LeuLeuOMe-mediated cytotoxicity was inhibited by E-64d. 
Calu-1 TRAIL concentration $(\mathrm{ng} / \mathrm{ml})$
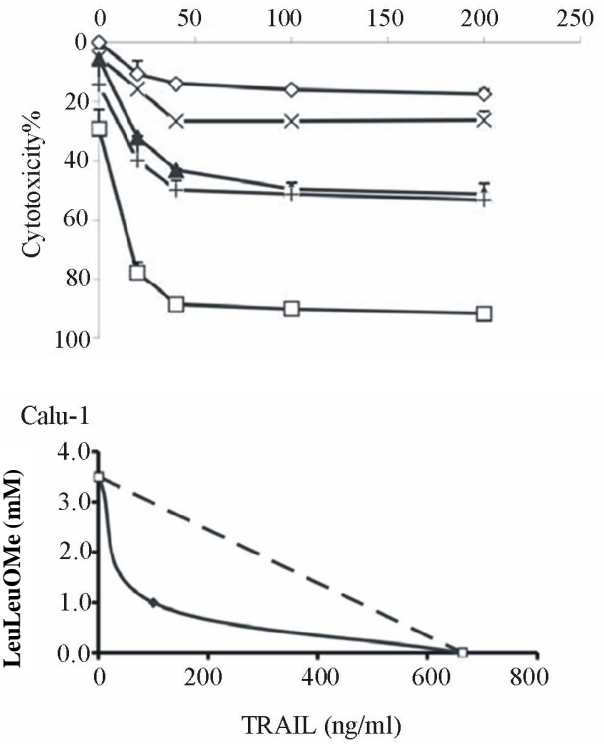

NCI-H460 TRAIL concentration $(\mathrm{ng} / \mathrm{ml})$

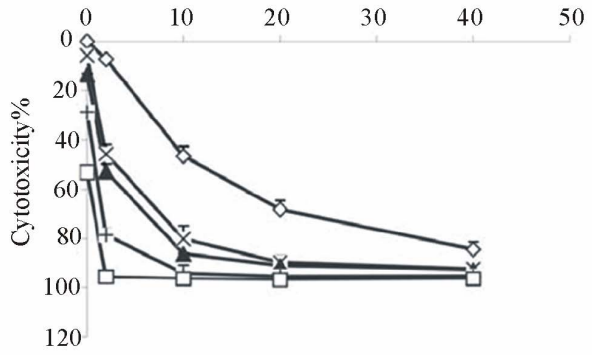

(a)

NCI-H460

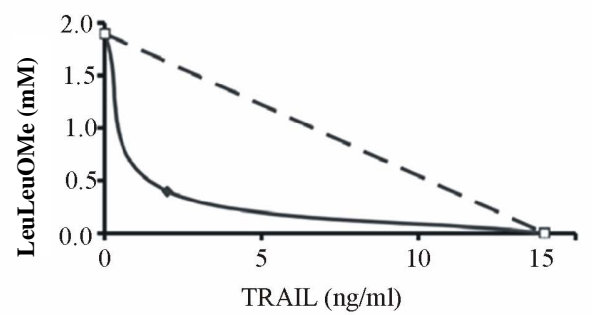

(b)

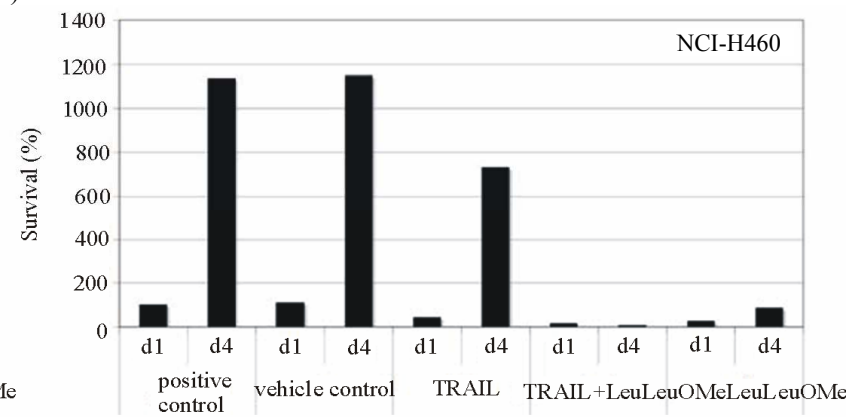

(c)

Figure 5. Synergistic effects of TRAIL and LeuLeuOMe on cytotoxicity in lung cancer cell lines. Calu-1 or NCI-H460 cells were treated with TRAIL and/or LeuLeuOMe as detailed below. Cytotoxicity was measured using SRB assay; each graph shows the mean \pm SD of 3 replicate measurements. a: Cytotoxicity after treatment for 6 hours with TRAIL alone (0 - 200 $\mathrm{ng} / \mathrm{ml}$ for Calu-1 cells; 0 - $40 \mathrm{ng} / \mathrm{ml}$ for NCI-H460 cells), LeuLeuOMe alone (0 - $2.0 \mathrm{mM})$, or combinations of the two with LeuLeuOMe at: $\diamond, 0 \mathrm{mM}$;, $0.2 \mathrm{mM} ; \leftrightarrow 0.4 \mathrm{mM}$; +, $1.0 \mathrm{mM}$; $\square, 2.0 \mathrm{mM}$. b: Isobolographs for $50 \%$ cytotoxicity in Calu-1 and NCI-H460 cells, both exhibiting concave curves that indicate synergy. c: Recovery of cells after treatment with TRAIL and/or LeuLeuOMe. Cells were treated on day 1 for 6 hours with TRAIL only (200 ng/ml for Calu-1; 40 ng/ml for H460), LeuLeuOMe only ( $2 \mathrm{mM}$ for each), or a combination of both (TRAIL at $200 \mathrm{ng} / \mathrm{ml}$ for Calu-1 and $2 \mathrm{ng} / \mathrm{ml}$ for H460, LeuLeuOMe at $\mathbf{2 m M}$ for each). After recovery for an additional 3.5 days in regular media, the surviving cell numbers were determined by SRB assay. d1, d4: percent of cells at day 1 or day 4 relative to positive control at day 1, respectively; positive control: media only, vehicle control: media plus DMSO solvent.

After co-treatment with TRAIL (40 ng/ml for Calu-1 cells, $10 \mathrm{ng} / \mathrm{ml}$ for NCI-H460 cells) plus $0.4 \mathrm{mM}$ LeuLeuOMe for 6 hours, both cell lines exhibited typical apoptotic morphological features, such as condensed and fragmented nuclei. Lysosomes apparently became fewer and enlarged, and mitochondria appeared to have lost their fine structure (Figure 6(c)).

Combination treatment resulted in increased expression of the early apoptosis marker protein Annexin $\mathrm{V}$ in both cell lines, and lead to some (Calu-1) or substantial (NCI-H460) nuclear collapse and DNA condensation (Figure 7). DNA condensation was visible even in NCI-H460 cells treated with only TRAIL or LeuLeuOMe, but not in Calu-1 cells. The numbers of affected cells observed by immunofluorescence and flow cytometry are slightly different, since for flow cytometry all attached and detached cells were used, whereas for Hoechst staining only attached cells were visualized. 


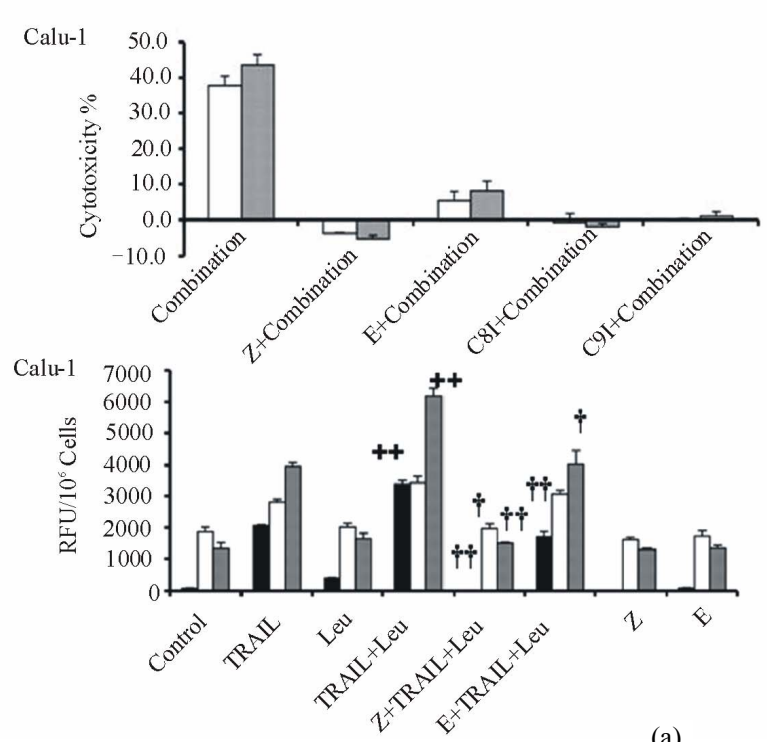

Calu-1

Control

LysoTracker

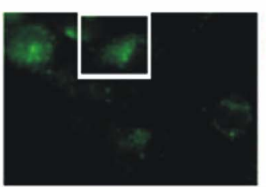

Combination

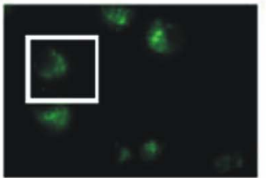

NCI-H460

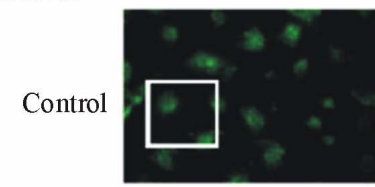

Combination

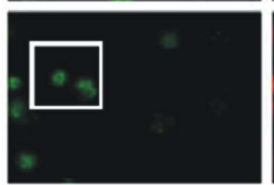

MitoTracker
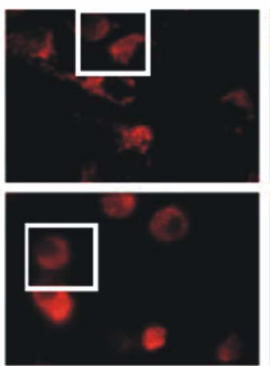

MitoTracker
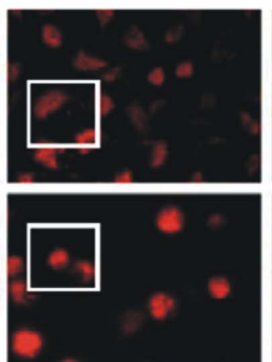

NCI-H460

NCI-H460

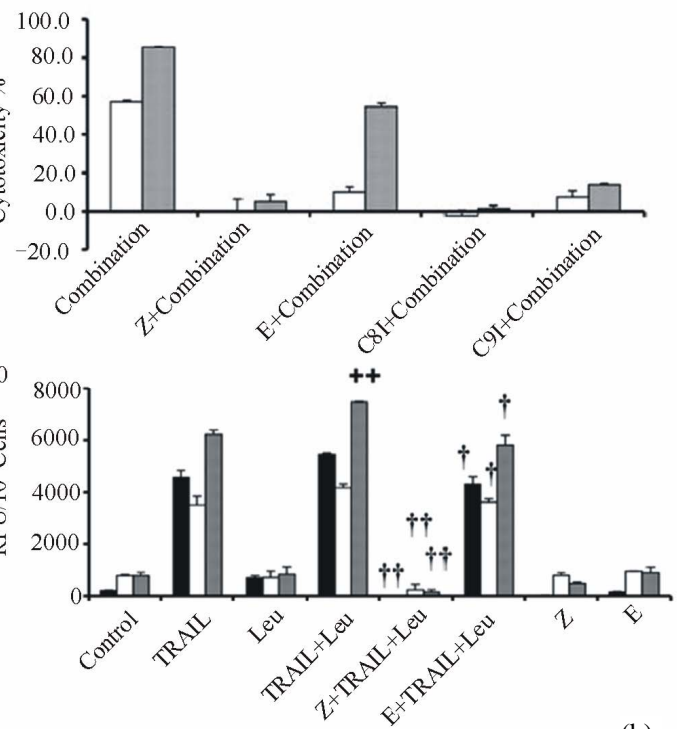

(b)

Insets
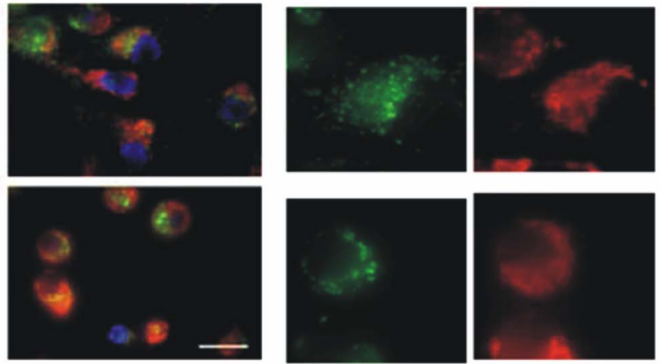

Overlay

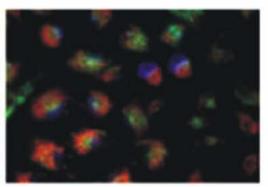

Insets
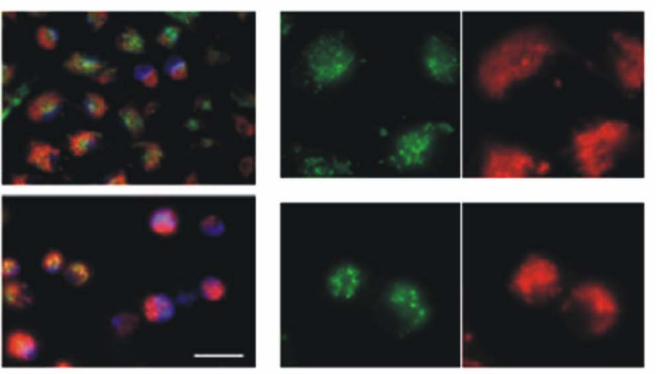

(c)

Figure 6. Effects of combination treatments on lung cancer cell lines. (a) Cytotoxicity after pretreatment of cells for 2 hours with protease inhibitors z-VAD-fmk (Z, $20 \mu \mathrm{M})$, E-64d (E, $20 \mu \mathrm{M})$, z-IETD-fmk (C8I, $20 \mu \mathrm{M}$ for Calu-1 cells; $80 \mu \mathrm{M}$ for NCI-H460 cells), or z-LEHD-fmk (C9I, $20 \mu \mathrm{M}$ for Calu-1 cells; $80 \mu \mathrm{M}$ for NCI-H460 cells). This was followed by combination treatment for Calu-1 cells (0.4 mM LeuLeuOMe plus $20 \mathrm{ng} / \mathrm{ml}$ TRAIL, open bars, or plus $40 \mathrm{ng} / \mathrm{ml}$ TRAIL, grey bars) or for NCI-H460 cells (0.4 mM LeuLeuOMe plus $2 \mathrm{ng} / \mathrm{ml}$ TRAIL, open bars, or plus $10 \mathrm{ng} / \mathrm{ml}$ TRAIL, grey bars). (b) Caspase activity after treatment with TRAIL alone (40 ng/ml for Calu-1 cells; $10 \mathrm{ng} / \mathrm{ml}$ for NCI-H460 cells), LeuLeuOMe alone (0.4 mM for both cells), or a combination (40 ng/ml TRAIL plus $0.4 \mathrm{mM}$ LeuLeuOMe for Calu-1 cells; $10 \mathrm{ng} / \mathrm{ml}$ TRAIL plus $0.4 \mathrm{mM}$ LeuLeuOMe for NCI-H460 cells); pre-treatment of cells with $20 \mu \mathrm{M}$ of z-VAD-fmk (Z) or E-64d (E) for 2 hours was done as in a. Activity for caspase-3 (black bars), caspase-8 (open bars), and caspase-9 (grey bars) is expressed in relative fluorescence units (RFU). $+/++$ vs. TRAIL, $+p<0.05,++p<0.01$; $\dagger / \dagger \dagger$ vs. the combination of TRAIL plus LeuLeuOMe, $\dagger p<0.05, \dagger+p<$ 0.01. (c) Fluorescence microscopy images of cells after combination treatment (40 ng/ml TRAIL plus $0.4 \mathrm{mM}$ LeuLeuOMe for Calu-1 cells; $10 \mathrm{ng} / \mathrm{ml}$ TRAIL plus $0.4 \mathrm{mM}$ LeuLeuOMe for NCI-H460 cells) and co-staining with LysoTracker Green DND-26, MitoTracker Red CMXRos and Hoechst 33342 (overlays, bar: $25 \mu \mathrm{m}$ ). Individual images for LysoTracker and MitoTracker are also shown together with selected enlarged regions (boxed insets: $40 \mu \mathrm{m}$ ). 


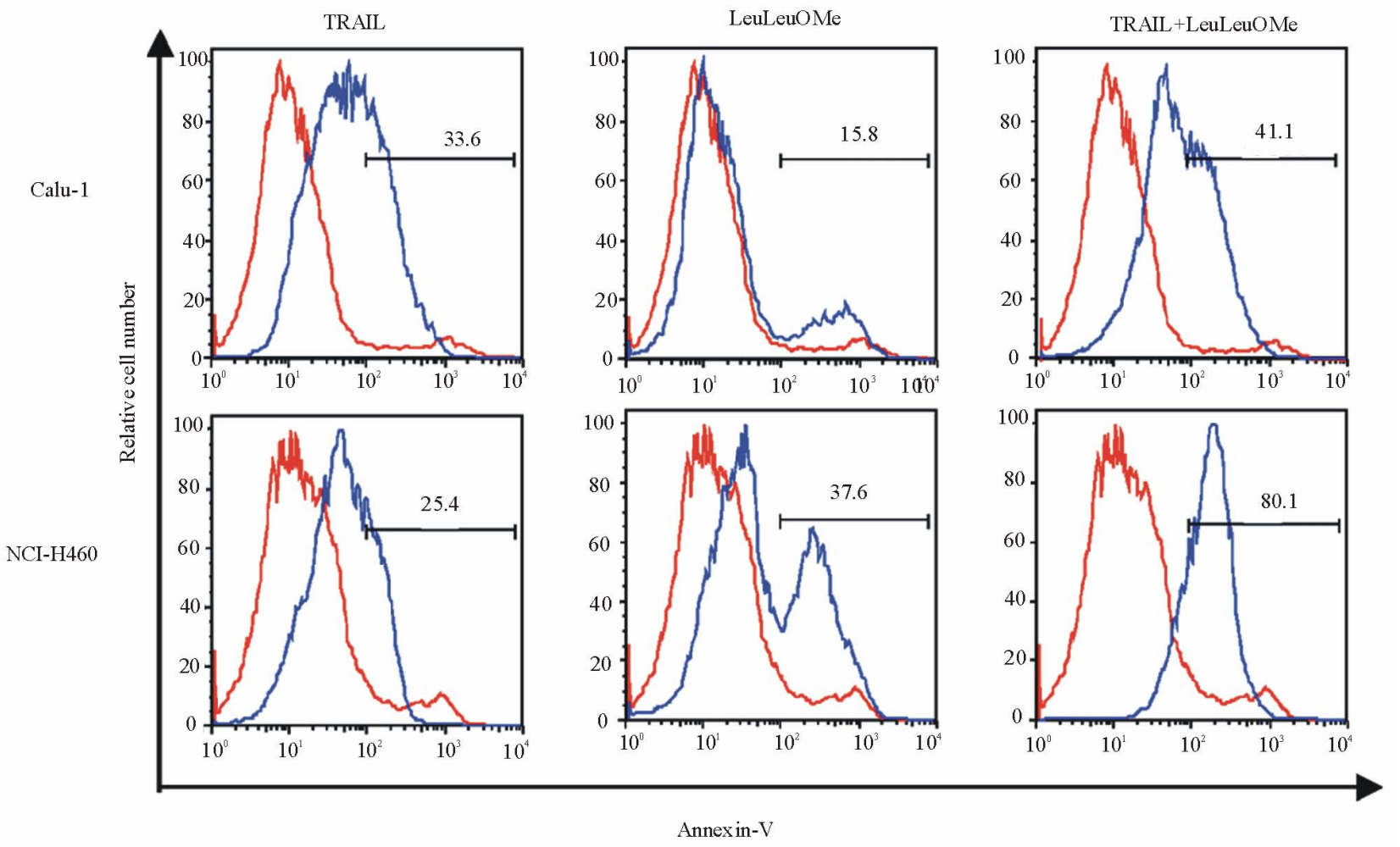

(a)
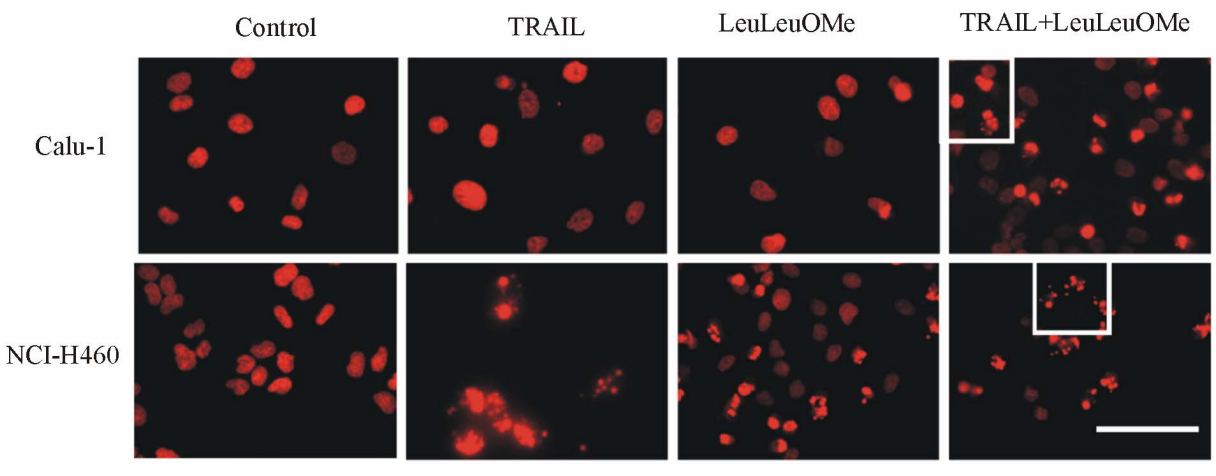

Inset

(b)

Figure 7. Combined treatment with TRAIL and LeuLeuOMe causes apoptosis in both TRAIL-resistant and TRAIL-sensitive lung cancer cell lines. a. Flow cytometry for Annexin V staining of Calu-1 and NCI-H460 cells treated for 6 hours with TRAIL only (200 ng/ml for Calu-1; $40 \mathrm{ng} / \mathrm{ml}$ for H460), LeuLeuOMe only ( $2 \mathrm{mM}$ for each), a combination of both (TRAIL at $200 \mathrm{ng} / \mathrm{ml}$ for Calu-1 or $2 \mathrm{ng} / \mathrm{ml}$ for H460, LeuLeuOMe at $2 \mathrm{mM}$ for each), or of untreated control cells. Treated cells are shown as blue lines, untreated control cells as red lines. b. Fluorescence images of nuclei stained with Hoechst dye of NCI-H460 and Calu-1 cells treated with TRAIL and/or LeuLeuOMe as in a (scale bar $2 \mu \mathrm{m}$ ). Selected areas (white boxes) are shown as $5 x$ magnified insets.

\section{Discussion}

We are exploring novel treatment options for facilitating cell death in lung cancers with intrinsic or acquired resistance to apoptosis-inducing therapeutic agents. As model system, we have used a TRAIL-resistant and a
TRAIL-sensitive lung carcinoma cell line, and LeuLeuOMe as lysosome-destabilizing drug. The molecular events that render some lung tumors resistant to TRAIL-mediated apoptosis, and the role of lysosomal proteases in this process, are unclear. TRAIL is a particularly promising therapeutic agent since it is non-toxic 
to normal cells but has consistently shown toxicity towards most tumor cells tested, making it suitable for local or even systemic delivery. Furthermore, various lysosome-destabilizing drugs are in fact available [26,28, 29,34-36], although none of them has actually been tested in the context of triggering lysosome-mediated apoptosis for therapeutic applications.

\subsection{Sensitivities to TRAIL Are Paralleled by Differential Sensitivities to LeuLeuOMe}

As described previously [32], Calu-1 cells were highly TRAIL-resistant, whereas NCI-H460 cells were very TRAIL-sensitive. We showed here that LeuLeuOMe sensitivity paralleled TRAIL sensitivity, although less pronounced. Interestingly, our treatment/recovery protocol showed that any low-level residual TRAIL resistance in NCI-H460 cells was only transient since the cells could re-establish most of their sensitivity over time.

Our data showed that TRAIL and LeuLeuOMe apparently use different but converging pathways for their cytotoxic effects, since their dose-response curves differed and cytotoxicities were differentially affected by a cysteine protease inhibitor (Figure 8). On the other hand, both pathways involve caspase-mediated events, since caspase activities increased after treatment and cytotoxic effects were totally blocked by a pan-caspase inhibitor. TRAIL activated all three caspases with the highest increase for caspase-3, whereas LeuLeuOMe activated mainly caspase- 3 and -9 but not caspase- 8 ; this response was also seen in the co-treatment regimens. Sensitivity to LeuLeuOMe was lessened by the cysteine protease inhibitor whereas TRAIL sensitivity was not affected, indicating that the LeuLeuOMe-mediated pathway involves lysosomal cysteine proteases, presumably cathepsin B and/or cathepsin L [14,24,25]. On the other hand, involvement of cathepsins has been reported for the TRAIL-mediated pathway as well, and alternative complementary pathways acting simultaneously with and without participation of cathepsins were observed in tumor cells [14,25-27]. Thus, involvement of lysosomal cathepsins appears to be tumor- or cell type-specific.

As predicted by our model, pre-incubation with the pan-caspase inhibitor z-VAD-fmk resulted in inhibition of cytotoxicity, which was paralleled by prevention of caspase activation for either TRAIL or LeuLeuOMe treatment. However, caspase activation was blocked by E-64d only for LeuLeuOMe-mediated but not for TRAIL-mediated cytotoxicity, again reflecting the differential involvement of cysteine proteases. When using inhibitors specific for either caspase- 8 or caspase-9, the residual cytotoxicity observed in the presence of the caspase-9 inhibitor suggests that the mitochondria-mediated pathway may be used as alternative but not essential

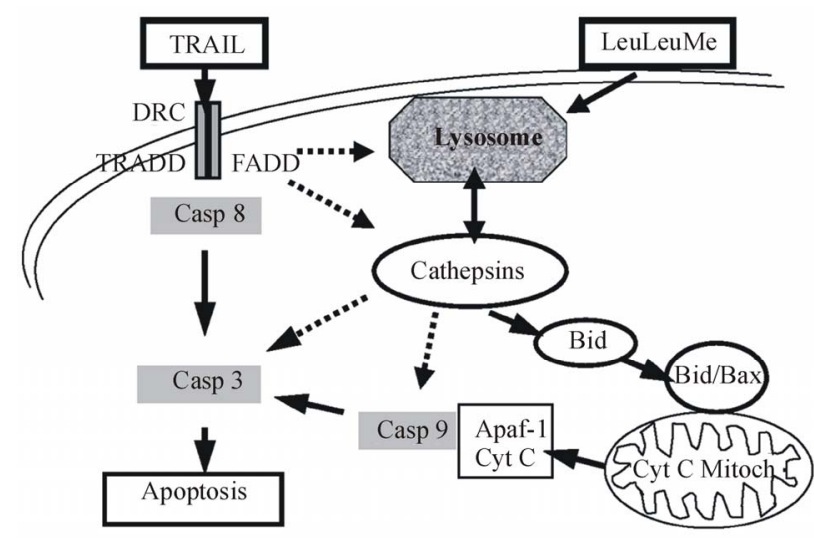

Figure 8. Molecular factors and interactions potentially involved in apoptosis pathways induced by the combination of TRAIL and LeuLeuOMe. Solid arrows indicate pathways with previously published experimental evidence; dashed arrows suggest potentially important hypothetical pathways.

pathway in this system. Such an amplification role has been described previously for this pathway [14,21].

\subsection{Synergistic Effects of TRAIL Plus LeuLeuOMe Combination Treatments}

An important observation with clinical implications was that TRAIL plus LeuLeuOMe co-treatment resulted in substantial TRAIL sensitization of the intrinsically resistant Calu-1 cells. This effect was clearly synergistic and may enable potential therapeutic application once further tested and optimized for additional cell lines in vitro and in vivo [29,30]. Also, the combination treatment elicited a cytotoxic effect from which both cell types could not recover after several days, whereas this effect was not seen for individual treatments with either TRAIL or LeuLeuOMe alone.

Pre-incubation with E-64d partially reduced the effect of combination treatment in both cell lines. This decreased cytotoxicity presumably was caused by inhibition of the LeuLeuOMe-induced effect only, since it reduced cytotoxicity to a level equal to the same TRAIL dose alone. Thus, E-64d only protected the cells from LeuLeuOMe-induced but not from TRAIL-induced cytotoxicity in the combination treatment. This confirmed that the TRAIL-induced pathway does not involve endogenous cysteine proteases, but rather involved only the caspase-dependent pathway. As for the individual treatments, synergistic cytotoxicity of the combination treatment in both cell lines could be completely inhibited by the pan-caspase inhibitor z-VAD-fmk, demonstrating that both TRAIL and LeuLeuOMe cytotoxicity involved caspase activation.

Direct observation of organelles in co-treated cells also 
showed that lysosomes became fewer in numbers, some of the residual lysosomes were enlarged, and that mitochondrial integrity was partially lost, reflecting an at least partial destabilization of these key organelles.

\subsection{Therapeutic Implications}

The long-term goal of this work is to validate the lysosomal apoptosis pathway and its therapeutic potential in vivo. A nude mouse xenograft model using human lung carcinoma cells and local co-administration of TRAIL and/or lysosome-destabilizing drugs will be a suitable test system for toxicity and efficacy studies. Tumor-specific delivery of lysosomotropic drug may be feasible using drug-conjugated nanoparticles to specifically target tumor cells. Conceivably, drug-mediated destabilization of lysosomes can sensitize lung cancer cells to TRAIL, and potentially to other cell death-inducing therapeutic agents $[29,30]$. Combined drug-TRAIL treatment for therapeutic applications may allow lowering systemic doses, resulting in less toxicity and higher efficacy than TRAIL or drug alone. This may lead to a novel strategy for preventing tumor progression and metastatic spread even of apoptosis-resistant lung tumors [26,28-30].

\subsection{Conclusions}

Intrinsic TRAIL resistance in lung carcinoma cell lines can be overcome by co-treatment with a lysosomedestabilizing drug. The cytotoxic effect of co-treatment with TRAIL plus a lysosome-disrupting drug is synergistic and substantially lowers the effective TRAIL dose. The lysosome-mediated apoptosis pathway involves cysteine proteases, whereas the TRAIL-mediated pathway does not. This synergistic co-treatment may enable novel therapeutic treatment options for lung carcinomas with intrinsic or acquired resistance to tumor cell cytotoxic treatment agents.

\section{Acknowledgements}

This work was supported by a grant from the Kentucky Lung Cancer Research Program to W.Z. We thank Dr. John W. Eaton for his valuable input in data interpretations and manuscript preparation, and Dr. Ulf Brunk for his critical comments on the manuscript.

\section{Conflict of Interest Statement}

None to declare for all authors.

\section{REFERENCES}

[1] S. Ramalingam and C. P. Belani, "Recent Advances in Targeted Therapy for Non-Small Cell Lung Cancer," Expert Opinion in Therapeutic Targets, Vol. 11, No. 2, 2007, pp. 245-257. doi:10.1517/14728222.11.2.245
[2] N. W. Choong, R. Salgia and E. E. Vokes, "Key Signaling Pathways and Targets in Lung Cancer Therapy," Clinical Lung Cancer, Vol. 8, No. 2, 2007, pp. S52-S60. doi:10.3816/CLC.2007.s.002

[3] L. R. Motadi, N. L. Misso, Z. Dlamini and K. D. Bhoola, "Molecular Genetics and Mechanisms of Apoptosis in Carcinomas of the Lung and Pleura: Therapeutic Targets," International Immunopharmacology, Vol. 7, No. 14, 2007, pp. 1934-1947.

doi:10.1016/j.intimp.2007.07.013

[4] M. Takahashi, O. Inanami, N. Kubota, M. Tsujitani, H. Yasui, A. Ogura, et al., "Enhancement of Cell Death by TNF Alpha-Related Apoptosis-Inducing Ligand (TRAIL) in Human Lung Carcinoma A549 Cells Exposed to X Rays under Hypoxia," Journal of Radiation Research, Vol. 48, No. 6, 2007, pp. 461-468. doi:10.1269/jrr.07028

[5] H. Zhuang, W. Jiang, W. Cheng, K. Qian, W. Dong, L. Cao, et al., "Down-Regulation of HSP27 Sensitizes TRAIL-Resistant Tumor Cell to TRAIL-Induced Apoptosis," Lung Cancer, Vol. 68, No. 1, 2010, pp. 27-38. doi:10.1016/j.lungcan.2009.05.014

[6] G. Mellier, S. Huang, K. Shenoy and S. Pervaiz, "TRAILing Death in Cancer," Molecular Aspects of Medicine, Vol. 31, No. 1, 2010, pp. 93-112.

doi:10.1016/j.mam.2009.12.002

[7] B. Pennarun, A. Meijer, E. G. de Vries, J. H. Kleibeuker, F. Kruyt and S. de Jong, "Playing the DISC: Turning on TRAIL Death Receptor-Mediated Apoptosis in Cancer," Biochimica Biophysica Acta, Vol. 1805, No. 2, 2010, pp. 123-140.

[8] J. Voortman, T. P. Resende, E. Abou, M. A. Hassan, G. Giaccone and F. A. Kruyt, "TRAIL Therapy in Non-Small Cell Lung Cancer Cells: Sensitization to Death Receptor-Mediated Apoptosis by Proteasome Inhibitor Bortezomib," Molecular Cancer Therapeutics, Vol. 6, No. 7, 2007, pp. 2103-2112. doi:10.1158/1535-7163.MCT-07-0167

[9] J. Y. Lee, S. Huerta-Yepez, M. Vega, S. Baritaki, D. A. Spandidos and B. Bonavida, "The NO TRAIL to YES TRAIL in Cancer Therapy," International Journal of Oncology, Vol. 31, No. 4, 2007, pp. 685-691.

[10] A. Ashkenazi, R. C. Pai, S. Fong, et al., "Safety and Antitumor Activity of Recombinant Soluble Apo2 Ligand," Journal of Clinical Investigation, Vol. 104, No. 2, 1999, pp. 155-162. doi:10.1172/JCI6926

[11] H. Walczak, R. E. Miller, K. Ariail, B. Gliniak, T. S. Griffith, M. Kubin, et al., "Tumoricidal Activity of Tumor Necrosis Factor-Related Apoptosis-Inducing Ligand in Vivo," Nature Medicine, Vol. 5, No. 2, 1999. pp. 157-163. doi:10.1038/5517

[12] E. Cretney, K. Takeda, H. Yagita, M. Glaccum, J. J. Peschon and M. J. Smyth, "Increased Susceptibility to Tumor Initiation and Metastasis in TNF-Related Apoptosis-Inducing Ligand-Deficient Mice," Journal of Immunology, Vol. 168, No. 3, 2002, pp. 1356-1361.

[13] F. Dong, L. Wang, J. J. Davis, W. Hu, L. Zhang, W. Guo, et al., "Eliminating Established Tumor in nu/nu Nude Mice by a Tumor Necrosis Factor-Alpha-Related Apop- 
tosis-Inducing Ligand-Armed Oncolytic Adenovirus," Clinical Cancer Research, Vol. 12, No. 17, 2006, pp. 5224-5230. doi:10.1158/1078-0432.CCR-06-0244

[14] N. S. Nagaraj, N. Vigneswaran and W. Zacharias, "Hypoxia Inhibits TRAIL-Induced Tumor Cell Apoptosis: Involvement of Lysosomal Cathepsins," Apoptosis, Vol. 12 , No. 1, 2007, pp. 125-139. doi:10.1007/s10495-006-0490-1

[15] P. A. Mayes, L. Campbell, M. S. Ricci, J. P. Plastaras, D. T. Dicker and W. S. El-Deiry, "Modulation of TRAILInduced Tumor Cell Apoptosis in a Hypoxic Environment," Cancer Biology \& Therapy, Vol. 4, No. 10, 2005, pp. 1068-1074. doi:10.4161/cbt.4.10.2255

[16] D. A. Nelson, T. T. Tan, A. B. Rabson, D. Anderson, K. Degenhardt and E. White, "Hypoxia and Defective Apoptosis Drive Genomic Instability and Tumorigenesis," Genes \& Development, Vol. 18, No. 17, 2004, pp. 2095-2107. doi:10.1101/gad.1204904

[17] N. S. Nagaraj, N. Vigneswaran and W. Zacharias, "Cathepsin B Mediates TRAIL-Induced Apoptosis in Oral Cancer Cells," Journal of Cancer Research \& Clinical Oncology, Vol. 132, No. 3, 2006, pp. 171-183. doi:10.1007/s00432-005-0053-9

[18] N. Vigneswaran, J. Wu, N. Nagaraj, K. Adler-Storthz and W. Zacharias, "Differential Susceptibility of Metastatic and Primary Oral Cancer Cells to TRAIL-Induced Apoptosis," International Journal of Oncology, Vol. 26, No. 1, 2005, pp. 103-112.

[19] N. Vigneswaran, D. C. Baucum, J. Wu, Y. Lou, J. Bouquot, S. Muller and W. Zacharias, "Repression of Tumor Necrosis Factor-Related Apoptosis-Inducing Ligand (TRAIL) but Not Its Receptors during Oral Cancer Progression," BMC Cancer, Vol. 7, 2007, p. 108. doi:10.1186/1471-2407-7-108

[20] N. W. Werneburg, M. E. Guicciardi, S. F. Bronk, S. H. Kaufmann and G. J. Gores, "Tumor Necrosis Factor-Related Apoptosis-Inducing Ligand Activates a Lysosomal Pathway of Apoptosis That is Regulated by Bcl-2 Proteins," Journal of Biological Chemistry, Vol. 282, No. 39, 2007, pp. 28960-28970. doi:10.1074/jbc.M705671200

[21] N. S. Nagaraj, N. Vigneswaran and W. Zacharias, "Hypoxia-Mediated Apoptosis in Oral Carcinoma Cells Occurs via Two Independent Pathways," Molecular Cancer, Vol. 3, 2004, p. 38. doi:10.1186/1476-4598-3-38

[22] T. Kurz, A. Terman, B. Gustafsson and U. T. Brunk, "Lysosomes in Iron Metabolism, Ageing and Apoptosis," Histochemistry and Cell Biology, Vol. 129, No. 2, 2008, pp. 389-406. doi:10.1007/s00418-008-0394-y

[23] P. Boya and G. Kroemer, "Lysosomal Membrane Permeabilization in Cell Death," Oncogene, Vol. 27, No. 50, 2008, pp. 6434-6451. doi:10.1038/onc.2008.310

[24] T. Kirkegaard and M. Jäättelä, "Lysosomal Involvement in Cell Death and Cancer," Biochimica Biophysica Acta, Vol. 1793, No. 4, 2009, pp. 746-754. doi:10.1016/j.bbamcr.2008.09.008
[25] A. Puissant, M. Dufies, S. Raynaud, J. P. Cassuto and P. Auberger, "Targeting Lysosomes to Eradicate ImatinibResistant Chronic Myelogenous Leukemia Cells," Leukemia, Vol. 24, No. 5, 2010, pp. 1099-1101. doi:10.1038/leu.2010.55

[26] U. Repnik and B. Turk, "Lysosomal-Mitochondrial Cross-Talk during Cell Death," Mitochondrion, Vol. 10, No. 6, 2010, pp. 662-669. doi:10.1016/j.mito.2010.07.008

[27] B. Joy, R. Sivadasan, T. E. Abraham, M. John, P. K. Sobhan and M. T. R. S. Seervi, "Lysosomal Destabilization and Cathepsin B Contributes for Cytochrome C Release and Caspase Activation in Embelin-Induced Apoptosis," Molecular Carcinogenesis, Vol. 49, No. 4, 2010, pp. 324-336.

[28] W. Ding, T. Cai, H. Zhu, R. Wu, C. Tu, L. Yang et al. "Synergistic Antitumor Effect of TRAIL in Combination with Sunitinib in Vitro and in Vivo," Cancer Letters, Vol. 293, No. 2, 2010, pp. 158-166. doi:10.1016/j.canlet.2010.01.005

[29] H. Zhu, W. J. Ding, R. Wu, Q. J. Weng, J. S. Lou, R. J. Jin, et al., "Synergistic Anti-Cancer Activity by the Combination of TRAIL/APO-2L and Celastrol," Cancer Investigations, Vol. 28, No. 1, 2010, pp. 23-32. . doi:10.3109/07357900903095664

[30] A.-C. Johansson, H. Appelqvist, C. Nilsson, K. Kagedal, K. Roberg and K. Oellinger, "Regulation of ApoptosisAssociated Lysosomal Membrane Permeabilization," Apoptosis, Vol. 15, No. 5, 2010, pp. 527-540. doi:10.1007/s10495-009-0452-5

[31] Y. P. Keepers, P. E., Pizao, G. J. Peters, J. van Ark-Otte, B. Winograd and H. M. Pinedo, "Comparison of the Sulforhodamine B Protein and Tetrazolium (MTT) Assays for in Vitro Chemosensitivity Testing," European Journal of Cancer, Vol. 27, No. 7, 1991, pp. 897-900. doi:10.1016/0277-5379(91)90142-Z

[32] S.-Y. Sun, P. Yue, J.-Y. Zhou, Y. Wang, H.-R. C. Kim, R. Lotan, et al., "Overexpression of BCL2 Blocks TNF-Related Apoptosis-Inducing Ligand (TRAIL)- Induced Apoptosis in Human Lung Cancer Cells," Biochemical and Biophysical Research Communications, Vol. 280, No. 3, 2001, pp. 788-797. doi: $10.1006 /$ bbrc. 2000.4218

[33] M. C. Berenbaum, "Synergy, Additivism and Antagonism in Immunosuppression," Clinical \& Experimental Immunology, Vol. 28, No. 1, 1977, pp. 1-18.

[34] H. Erdal, M. Berndtsson, J. Castro, U. Brunk, M. C. Shoshan and S. Linder, "Induction of Lysosomal Membrane Permeabilization by Compounds that Activate P53- Independent Apoptosis," Proceedings of the National Academy of Sciences USA, Vol. 102, No. 1, 2005, pp. 192-197. doi:10.1073/pnas.0408592102

[35] J. R. Piccotti, M. S. LaGattuta, S. A. Knight, A. J. Gonzales and M. R. Bleavins, "Induction of Apoptosis by Cationic Amphiphilic Drugs Amiodarone and Imipramine," Drug \& Chemical Toxicology, Vol. 28, No. 1, 2005, pp. 117-133.

[36] L. Groth-Pedersen, M. S. Ostenfeld, M. Hoyer-Hansen, J. 
Nylandsted and M. Jaattela, "Vincristine Induces Dramatic Lysosomal Changes and Sensitizes Cancer Cells to Lysosome-Destabilizing Siramesine," Cancer Research,
Vol. 67, No. 5, 2007, pp. 2217-2225. doi:10.1158/0008-5472.CAN-06-3520 